\title{
Linospora ceuthocarpa on aspen (Populus tremula) in Finland
}

\author{
HARRISON O. KOJWANG and TIMO KURKELA
}

KOJWANG, H.O. \& KURKELA, T. 1984: Linospora ceuthocarpa on aspen (Populus tremula) in Finland. - Karstenia 24: 33-40.

The maturation of the perithecia of the pathogenic pyrenomycete Linospora ceuthocarpa (Fr.) Lind, its spore liberation, mode of infection, and the development of symptoms on aspen leaves were investigated. The study also included the histological examination of infected leaves and a description of the cultural characteristics of the fungus. Perithecia matured in the spring, spore liberation began in the third week of June, followed by dispersal and infection. Lesions appeared on aspen leaves by the third to fourth week of July. Fast growing semimature leaves were most susceptible.

Harrison O. Kojwang, Faculty of Agriculture (Department of Forestry), University of Nairobi, P.O. Box 29053, Kabete, Nairobi, Kenya

Timo Kurkela, The Finnish Forest Research Institute, Unioninkatu 40 A, SF-00170

Helsinki, Finland

\section{Introduction}

Two species of the genus Linospora Fuckel occur in Finland, of which the first, L. ceuthocarpa (Fr.) Lind, infects the leaves of common aspen (Populus tremula L.); and the other, L. capreae (DC.) Fuckel, occurs on the leaves of Salix caprea L. L. ceuthocarpa has been observed in many parts of Europe on the fallen leaves of P. tremula. Pinon and Morelet (1975) tested its ability to attack aspen and several poplar species in France. In India and Pakistan the fungus has been reported by Quraishi and Jamal (1969) as causing leaf spots on Populus ciliata Wall. L. ceuthocarpa constitutes little danger for aspen in Finland, but it could be a potential threat where rapidly growing poplars are more important.

According to Pinon and Morelet (1975), the ascospores of $L$. ceuthocarpa infect primarily the semi-mature leaves of $P$. tremula in late June, symptoms of the disease appearing within one month of infection. The diseased leaves fall prematurely, about one month before normal leaf fall; and dark brown spots can usually be seen on a number of them, thickly formed along the main veins. These spots are composed of young, pseudostromatic tissue enclosing perithecial initials.

The fallen leaves overwinter; and in the early spring of the following year in southern Finland, the spots have become $0.5-1 \mathrm{~mm}$ wide black, shiny, round to elliptical epumpent pseudostromata containing nearly mature perithecia.

The aim of this study was to investigate the biology of $L$. ceuthocarpa, its life cycle, and the histology of the development of perithecia, as well as the histology of infected aspen leaves.

\section{Taxonomy of the pathogen}

L. ceuthocarpa belongs to the family Valsaceae of the order Diaporthales (Sphaeriales s.lat.) (Eriksson
1983). The correct author citation seems to be $L$. ceuthocarpa (Fr.) Lind rather than L. ceuthocarpa (Fr.) Munk ex Morelet, since Lind (1913) clearly validly published the combination, as correctly indicated by Munk (1957), for instance. Karsten (1873) reported the fungus from Finland as Ceuthocarpon populinum (Fr.) Karst. In other countries several additional names have been adopted for the species, e.g. Linospora populina (Pers.) Wint. (Winter 1887, Pinon \& Morelet 1975).

The conidial stage may be called Asteroma frondicola (Fr.) Morelet according to Sutton (1980); and this stage also has several synonyms, e.g. Titaeosporina tremulae (Lib.) van Luyk (used by Pinon \& Morelet 1975), and Gloeosporium tremulae (Lib.) Pass.

\section{Materials and methods}

\section{Leaf samples}

Leaf samples for the study were collected in southern Finland. The sampling areas were characterized by open, clear-cut sites supporting aspen coppice. $L$. ceuthocarpa was also found, e.g., on leaf litter in nearmature pine stands with understory of aspen coppice.

The samples were collected in the following places: Rusutjärvi

Etelä-Häme: Tammela, Kyynärä

Etelä-Häme: Loppi,

Ojajoki

Etelä-Savo:

Leivonmäki, Kivisuo

Etelä-Pohjanmaa:

Maksamaa, Bodö

\section{Location}

Uusimaa: Tuusula,
Grid $27^{\circ} \mathrm{E}$ Date of collection

13.V.1982, 30.V.1982

$670: 38$ and 24.IX.1982

673:31 8.V.1982, 18.VI.1982

674:36 13.V.1982, 17.V.1982

686:44 29.V.1982

$702: 24 \quad 9 . V .1982$ 
In May, perithecia on the leaves were not mature. To discover when natural spore discharge occurs and to obtain material for inoculation tests, some of the leaf samples from each location were placed outdoors and kept in a horizontal position inside 50 by $50 \mathrm{~cm}$ nylon net bags. In each bag $80-100$ leaves were placed in one layer. The lawn where the bags were placed was cut regularly and the place was shaded from direct sunshine during $\mathrm{c}$. half of the daylight hours. The development of the fungus was checked regularly. Some samples were also later collected from the original collection sites in Tammela, Loppi, and Tuusula.

The collected specimens were deposited in the Herbarium of the Finnish Forest Research Institute (HFR).

\section{Histological studies}

Another series of leaf samples with developing lesions caused by $L$. ceuthocarpa was collected from May to October. From these leaves, pieces of affected tissue were cut, fixed in FAA (formaldehyde-alcohol-acetic acid), dehydrated in alcohol and embedded in paraffin. The samples were sectioned with a microtome and stained according to the fast green - safranin method described by Jensen (1962). These sections were used in the histological study of both the development of the perithecia and the extention of mycelium in leaf lesions after inoculation or natural infection.

\section{Measurement of perithecia}

From the upper side of each selected leaf, at least 20 perithecia were measured. The leaves were rinsed for two minutes and laid flat below a dissecting microscope. The longest and shortest diameters of each perithecium were measured. Those perithecia which had formed adjacent to each other were not measured.

The same leaf samples were used to measure asci and ascospores. The mass of asci and ascospores was dropped and spread on the slides, suspended within a drop of a liquid mixture of stain (cotton blue) and Kaiser's glycerine which provided a semipermanent slide. The asci were measured together with their short pedicels. Only ascospores straight in appearance were measured, although some of the filiform spores were curved or spirally twisted. About 120 asci and ascospores were measured in the collections from each source.

\section{Isolation methods}

In the first section of the studies, L. ceuthocarpa was isolated from overwintered aspen leaves. The leaves were surface sterilized in $5 \%$ hydrogen peroxide for five minutes. The immature perithecia were aseptically removed from the pseudostromatic laminae, rinsed for about 10 seconds in sterile water, and then plated out. Two types of substrate were used for the isolations; $1.5 \%$ malt extract agar and malt extract with lactic acid. Isolates in Petri dishes were incubated at a temperature of $15^{\circ} \mathrm{C}$. The second set of isolates, made in late July and early September, comprised leaves at various stages of infection on growing trees as well as prematurely fallen leaves of $P$. tremula. This included c. one-month-old natural infections showing slight chlorosis, leaves showing young reddish-brown spots along the main veins, and inoculated leaves showing brown or grey lesions extending along the main veins. Leaves were again surfacesterilized for $5-7$ minutes. Bits of leaf tissue from the advancing margin of the lesion or newly formed perithecial initials (brown spots in the lesion) were removed, crushed in sterile water and incubated in Petri dishes on the same substrate as above at temperature of 18 to $22^{\circ} \mathrm{C}$.

Isolations were also made using ascospores. Since single ascospores were difficult to obtain and did not germinate well, entire or broken asci with a bundle of ascospores were used.

\section{Fungus cultures}

Equal mycelial discs were selected from two-week-old pure spore cultures, transferred to agar plates containing $2 \%$ malt extract, and incubated at temperatures of $5,15,18,22$, and $25^{\circ} \mathrm{C}$, with ten plates for each temperature. After one week and then on every fourth day for one month, black circles were drawn under the plates along the edge of mycelial colonies to follow the development of colony diameters.

The fungus was also grown on wheat grain. Grains which had been soaked in water for 12 hours were put into twelve, $250 \mathrm{ml}$ conical flasks to a depth of $1.5 \mathrm{~cm}$, after which the flasks were autoclaved, inoculated, and incubated under regulated light at a temperature of $15^{\circ} \mathrm{C}$.

\section{Maturation of perithecia}

Samples from the exposed leaves were examined after every three days until the first evidences of spore liberation. At the onset of ascospore liberation, a sample of ten leaves was selected from each source. The leaves were rinsed for five minutes, and then placed in a dew chamber which was equipped with two $240 \mathrm{~W}$ mercury lamps one meter above the leaves. The incubation temperature was $15-17^{\circ} \mathrm{C}$. The illumination was controlled to give a daily, sixteen-hour light period.

To monitor the entire period over which spores were liberated after they were wetted, an experiment was arranged in the dew chamber. Five leaves exhibiting good perithecial development were chosen for each source and fastened to the bottoms of Petri dishes which were thereafter inverted over vaseline coated glass slides at a distance of approximately one $\mathrm{cm}$. These slides were replaced with fresh ones every 24 hours until no more or negligible amounts of spores could be observed.

\section{Inoculation experiments and spore germination} Inoculations were made in June, two days after the confirmation of the onset of spore liberation in nature. Twelve potted one-year-old seedlings had been prepared for the inoculations. In addition, five young, naturally regenerated aspen saplings were selected in the field, on a site where naturally infected overwintered fallen leaves had not been observed. Inoculum was prepared in three different ways: Set one consisted of strips of naturally infected overwintered leaves containing mature perithecia. Set two was asci-ascospore suspensions, and set three pure ascospore cultures.

As inoculum, leaf strips with perithecia were pinned, slightly curved, above healthy leaf surfaces taking care that they did not completely block the areas beneath them from light. Some were also placed on the underside of the leaves. Leaves of different ages were represented. Most of the inoculum was prepared from diseased leaf samples collected from Tammela and Tuusula. Potted aspen seedlings were inoculated and transferred to a dew chamber. The plants were kept in the dew chamber for one week, after which the inoculum was removed and the seedlings taken into a glassplastic shelter where they were watered daily.

In the inoculations using mycelium from cultures, the mycelium grown on agar surface was gently smeared mainly on and along side the main leaf veins, with only a bit on the intercostal regions. An extra modification was that half of the leaves were wounded by inflicting tiny, gentle pin-pricks on circular areas, about one $\mathrm{cm}$ in diameter. This lot of seedlings was taken directly into the glass-plastic shelter and 

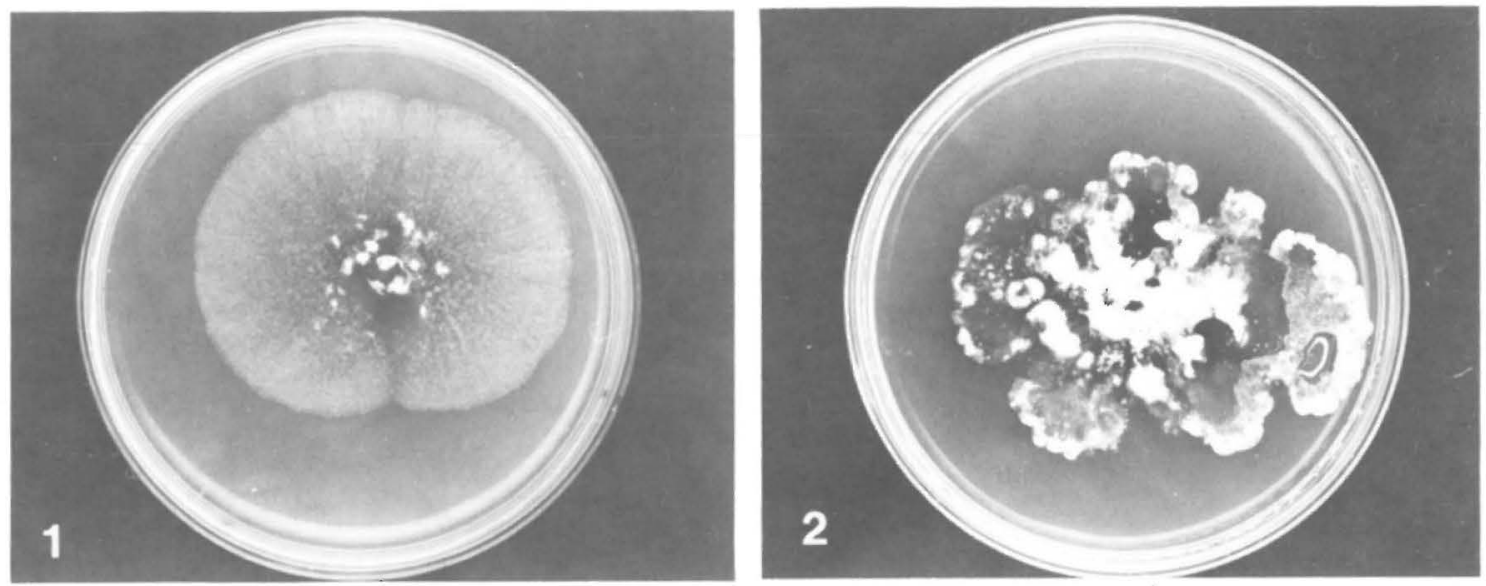

Figs. 1-2. Mycelial colonies of Linospora ceuthocarpa on malt extract agar. - 1: Growth at a favorable temperature. - 2: A culture incubated first at $25^{\circ} \mathrm{C}$ (unfavorable temp.), and then at $15^{\circ} \mathrm{C}$ (favorable temp.).

sprayed daily with water except on cool, cloudy days. Control leaves were smeared only with uncontaminated agar.

Field inoculations were made on the five healthy seedlings with no signs of Linospora attack. Spore suspensions for the field inoculations were prepared from the leaf samples with mature perithecia by a five-minute surface-sterilization with $3 \%$ hydrogen peroxide solution. The mature cream-whitish perithecia were aseptically removed from their pseudostromatic covering and crushed in sterile water. About 100 $\mathrm{ml}$ of asci-ascospore suspension was prepared and fed into sterile syringes. The spore density was not counted since only proof of the pathogenicity of the fungus was of primary interest. From each of the five aspen seedlings, three twings were selected and sprayed with a fine mist of water; then about thirty leaves were inoculated with the suspension and kept in plastic bags for one week. Two twigs were covered only with plastic bags without inoculum, to serve as controls. The first observations were made after two weeks. Weekly observations followed until leaf fall began in nature in late September, three months later.

Germination tests of asci-ascospore suspensions prepared aseptically were made both in water agar and plain water and incubated at temperatures of 18 and $22^{\circ} \mathrm{C}$, both of which had been associated with favorable growth of mycelial colonies. Checks on germination were made under a microscope after the 6 th, 12 th, 24 th, and 36 th hour. The experiment was done under light.

\section{Results}

\section{Fungus cultures}

The fungus $L$. ceuthocarpa was isolated repeatedly in the summer of 1982 from ascospores, immature perithecia, and tissue plantings of infected leaves. Malt extract agar was suitable for isolating the fungus from freshly infected leaves at the margin of lesions. Lactic acid agar was better for isolating the fungus from old, disintegrating tissue. Isolates from different origins appeared similar, except that those spore cultures on $2 \%$ mal extract agar at a temperature of $22^{\circ} \mathrm{C}$ grew faster than the rest.

On two-week-old cultures, the mycelium grown at a temperature of $22^{\circ} \mathrm{C}$ on malt extract agar were whitish in appearance (Fig. 1) while under the microscope hyphae were hyaline, septate with oily droplets, and having cells measuring $2.3-5 \times 22.5-$ $32 \mu \mathrm{m}$. However, the peripheral cells could be as long as $60 \mu \mathrm{m}$ with septation occurring later. On onemonth and older cultures, the mycelium appeared yellowish-brown, commonly with blisters and yellowish tufts; and several had a cottonous appearance in concentric zones near the margin of the colonies. By this time the immersed mycelium appeared dark; and little aerial growth was seen except for the tufts. Occasionally the growth pattern was fan-shaped (Fig. 2 ), otherwise a number of plates exhibited an almost symmetrical growth pattern.

Temperatures of 5 and $25^{\circ} \mathrm{C}$ inhibited growth after about one week and the immersed mycelium was dark, with a dark pigment diffusion into the agar below the mycelium. When these plates were taken into a $15^{\circ} \mathrm{C}$ incubator one month later, their mycelia started growing, quite asymmetrically. Growth of the fungus was promoted by incubation temperatures of 15,18 , and $22^{\circ} \mathrm{C}$, where the colony diameters after one month were 35,38 , and $43 \mathrm{~mm}$ on average. At $15^{\circ}$ $\mathrm{C}$, the fungus tended to have asymmetrical colonies with fan-shaped growth, forming patches of yellowish-brown mycelial tufts after one month, in addition to the hyaline, active, well-branched, partly immersed mycelia at the colony edges.

The fungus grew slowly on wheat grains. It took about 45 days for the yellowish-brown mycelium to colonize the upper surface of the mass of grains. In all the flasks the fungus exhibited weak sporulation. The conidia had slightly rounded ends (Fig. 3), whereas the conidia from the leaf specimen sent to the authors by Dr. J. Pinon from France had sharp ends. The conidia both in the culture and in the specimen, measured the same length and width: $6-9 \times 2.5-3$ $\mu \mathrm{m}$. The conidiogenous cells of $A$. frondicola are lageniform to cylindrical, $7-12 \times 2-3 \mu \mathrm{m}$, conidia straight, fusiform, $5-9 \times 2-2.5 \mu \mathrm{m}$, often larger, up to 24 long and anastomosing (Sutton 1980). 
3
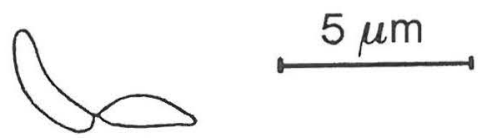

8
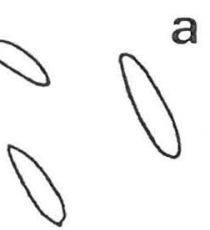

a

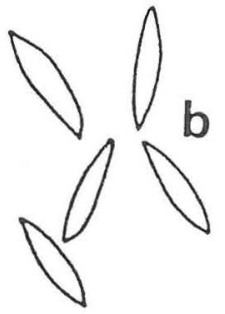

Fig. 3. L. ceuthocarpa. a) Conidia produced on wheat grains. b) Conidia formed naturally on the leaves on Populus tremula in France.

\section{Histology}

The leaf samples collected in September (18.IX. and 24.IX.1982) from Tuusula provided 4 distinct stages of the development of perithecia. The first specimen consisted of leaves which had lesions with bleached greenish-grey centres but which had not yet exhibited
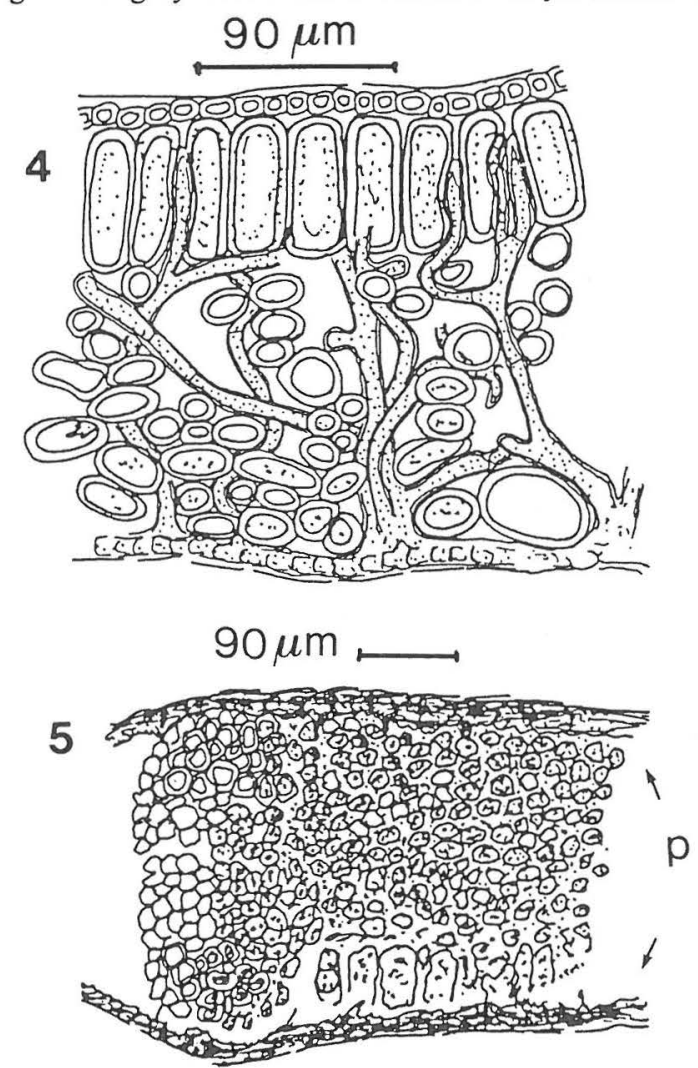

any signs of perithecial initials when viewed under a dissecting microscope. Hyphae were growing horizontally within the thin layer of the lower epidermal cells, sending ramifying branches mainly through the cells of the spongy mesophyll. These broad hyphae, 3-7 $\mu \mathrm{m}$, were mainly intercellular both in the mesophyll and palisade layers. The leaf cells among the hyphae did not appear collapsed. Occasionally some intercellular hyphae appeared to have sent branches into cell cytoplasm, but not clearly enough for us to speak confidently of haustorial formation. The hyphae were concentrated near the main leaf veins (Fig. 4).

A week later, the mesophyll near the main veins was impregnated with some darkish appearing fungal tissue, and the cells were now tightly packed. Above and below this region, on the upper and lower epidermis, layers of dark tissue were forming and thickening into the leaf. Even vascular tissue was gradually filled with this fungal material (Fig. 5). This stage represents the formation of the pseudostromatic tissue within which perithecial initials are formed, singly or occasionally in pairs along the main veins.

Within the pseudostroma, there was a structure, in the middle or nearer the upper epidermis, consisting of a circular wall $3-4$ cells thick, each cell measuring
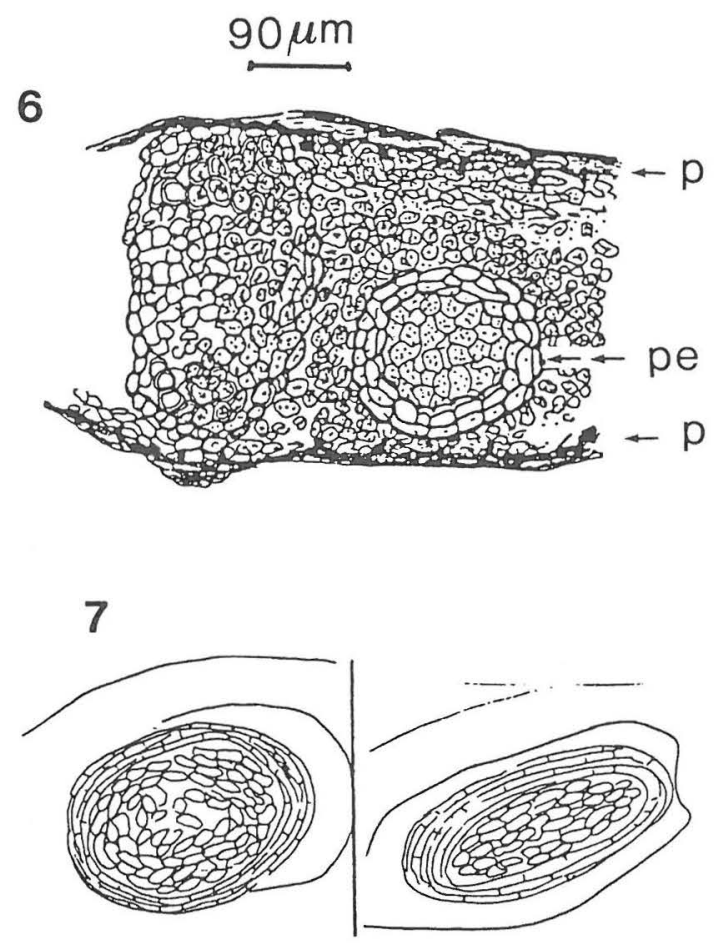

Figs. 4-7. Histology of the development of $L$. ceuthocarpa in the tissue of aspen leaves. - 4: Mainly intercellular hyphae at the edge of extending leaf lesion, lower epidermal cells filled with mycelium, the leaf cells are not collapsed. - 5: A later stage of development, leaf tissue impregnated with mycelium, dark fungal material, forming pseudostromata ( $p$ ), accumulated in the upper and lower epidermis. - 6: Pseudostromata (p) covering an initial of a perithecium (pe). - 7: Stages of perithecia during the late autumn. 
$9-16 \times 1-9 \mu \mathrm{m}$. Within this wall apparently undifferentiated pseudoparenchyma lay, constituting perithecial initials in the early stages of development. The parallel, dark coloured pseudostromatic laminae which eventually connect on both ends of the perithecia had by then grown thicker and darker in color (Fig. 6). Commonly young perithecia which had been collected in early May had died and were replaced by other fungi within the pseudostromata. The thick-walled hyphae of the fungus appeared brown in microtome slides.

Later development appeared to be by way of the elongation and probably further division of the cells of the perithecial walls, which appeared thinner and stretched. The pseudoparenchyma inside exhibited a higher stage of differentation with oval cells, 26-30 $\mu \mathrm{m}$ long, which apparently were the young asci and paraphyses (Fig. 7). This stage overwinters within the protective pseudostromata. Samples from the infected leaves collected shortly after snow melt showed that the young perithecia had grown larger and the asci much longer during the winter. In samples taken from Leivonmäki, where the development of perithecia came later than the rest, the immature asci measured $55-100 \times 5-7 \mu \mathrm{m}$ while in samples from Tuusula they measured $100-120 \times 5-9 \mu \mathrm{m}$.

The pseudostromata (stromatic layer $48-50 \mu \mathrm{m}$ thick) were black, opaque, circular to elliptical, $0,5-$ $1 \mathrm{~mm}$ in diameter, and equally visible on both sides of the leaf (Fig. 8). The dorsal and ventral parts consisted of indistinct, blackened cells and were joined at both ends of the perithecia by blackened cells, 6-11 $\mathrm{m}$ in diameter, growing in the mesophyll. Singly formed perithecia measured $285-400 \times 195-$ $215 \mu \mathrm{m}$. The beaks were laterally formed and grew as small buds into the pseudostromata for a short distance, after which they extended vertically outside, perpendicular to the leaf surface. The beaks consisted of hyaline paraphyses which were specialized in the central core into clubshaped ends obliquely arranged, facing upwards quarding the ostiole, 280-330 $x$ 64-75 $\mu \mathrm{m}$ (Figs. 9-11). The perithecial walls (peridia) consisted of $3-5$ cell layers (each about 4 $\mu \mathrm{m}$ thick) having an overall thickness of $14-23 \mu \mathrm{m}$, the inner cells being hyaline and the outer cells slightly yellowish-brown or slightly olive. The asci were long, hyaline, cylindrical, and covered by a thin layer of mucilage. The apical appratus stained blue by iodine consisted of two, small, closely spaced, elongate refractive bodies quarding the apical pore (Fig. 12). Mature asci $178-230 \times(5) 7-9(12) \mu \mathrm{m}$, arranged horizontally. Ascospores $137-300 \times 1,5-$ $2 \mu \mathrm{m}$, long, filiform, hyaline and multiseptate, with up to 14 septa in some ascospores, normally eight within the asci, tightly arranged, and often spirally twisted around each other (Fig. 13).

\section{Spore liberation and germination}

By the 18th of June, the first perithecial beaks in the more southern collections of Loppi, Tammela, and Tuusula had fully developed. They appeared dark brown to creamy around the ostiole through which the first ascospores were ejected by the 21 st of June, following two successive rain showers in southern

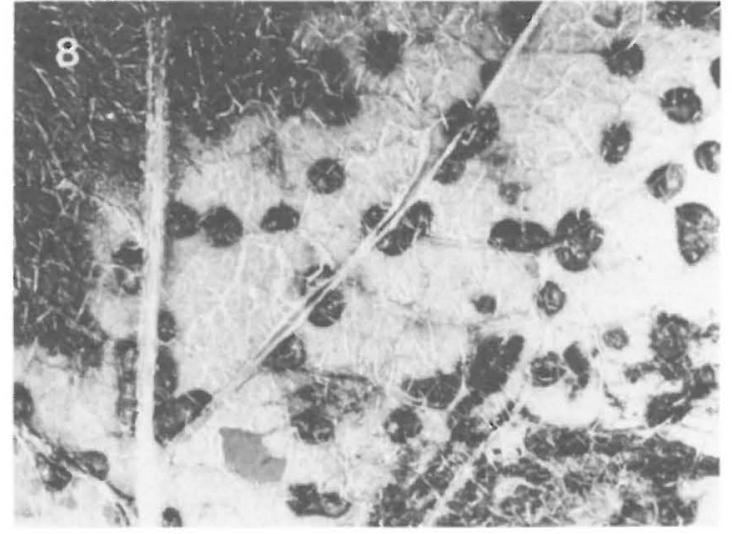

Fig. 8. Fully developed pseudostromata of $L$. ceuthocarpa on aspen leaf during the spring, $\times 10$.

Finland, and also in the laboratory when they were moistened. Often whole asci were ejected, although occasionally the walls had burst, releasing free ascospores (Fig. 14). The ascospores were surrounded by a thin layer of mucilage.

Perithecia on the leaves collected from Leivonmäki and Maksamaa had weaker and later development. Most of them failed to mature, except for the few that had fully developed perithecial beaks two weeks after the first lot of perithecia began liberating ascospores. This delayed development in the northern collections was also evident in a comparison of the sizes of asci and ascospores from different samples measured at the same time. Asci and ascospores elongated a great deal just before maturing. Spore liberation lasted for one month in the laboratory, and from late June to the second week of August in the field.

Single ascospores largely failed to germinate except for a very few, while most of the germination occurred on groups of ascospores or ascospores still bound by the ascal walls (Fig. 15). Germination in water agar was much greater than in free water, and germ tubes appeared after 12 hours, achieving prominence after 36 hours when incubated at 18 and $22^{\circ} \mathrm{C}$. More than one germ tube could develope from each ascospore.

\section{Disease development}

On naturally infected leaves, infections on fastgrowing near-mature leaves started as small slightly chlorotic spots in mid-July, enlarging with irregular margins most rapidly in arms along the main leaf veins (Fig. 16) before spreading into the intercostal regions. The lesions took on a greenish-grey bleached appearance; occasionally they spread in a zonate manner. The development of perithecial initials began in early August and was clearly seen as darkbrownish to reddish spots on both sides of the leaves, thickly formed along the main veins. Soon afterwards, in late August, the infected leaves started to fall prematurely, at which small, even lesions enlarged rapidly and formed perithecial initials on 

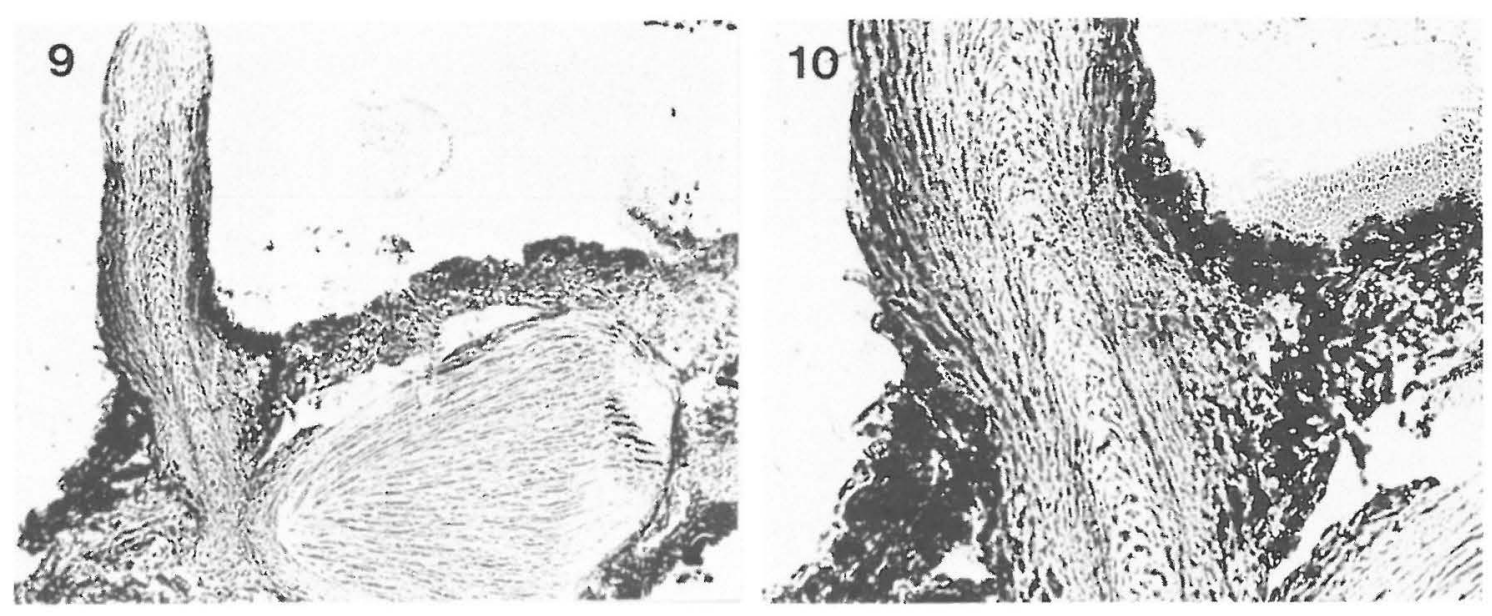

\section{1}

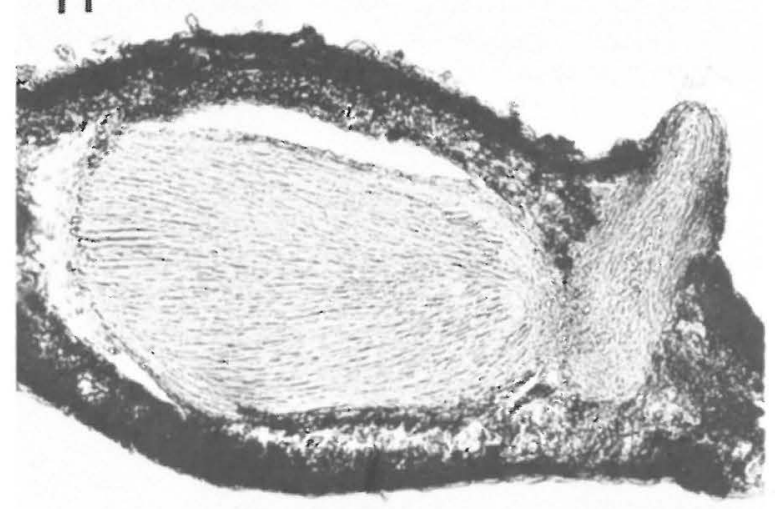

12
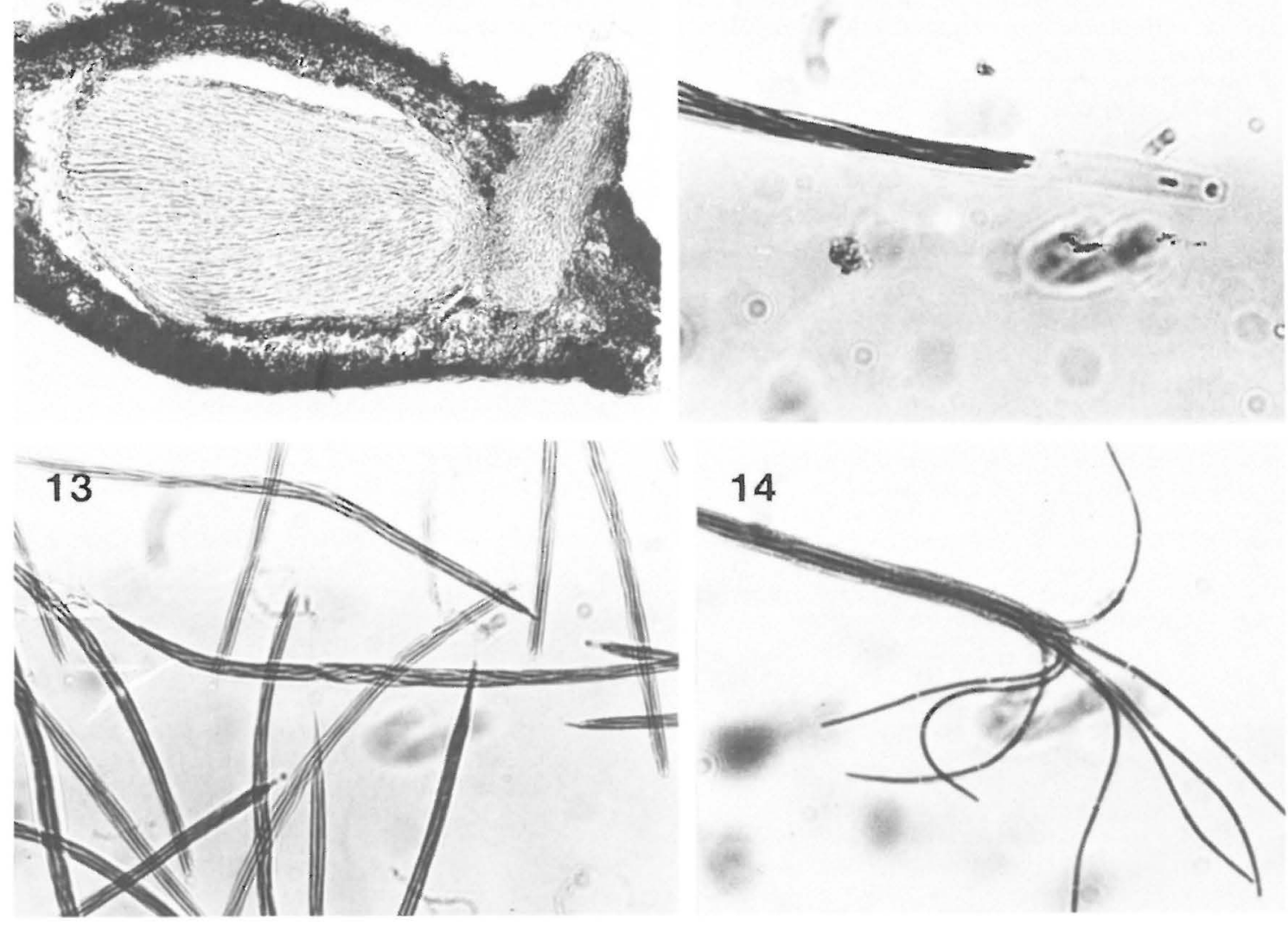

Figs. 9-14. L. ceuthocarpa. - 9: Cross section of mature perithecium, $\times 140 .-10$ : Perithecial beak and ostiolum, $\times 420$. 11: Immature perithecium with a developing beak, $\times 140 .-12$ : An ascus with its apical apparatus, $\times 420$. -13 : Asci liberated by perithecia, $\times 350$. -14 : A broken ascus with eight filiform ascospores, $\times 420$. 

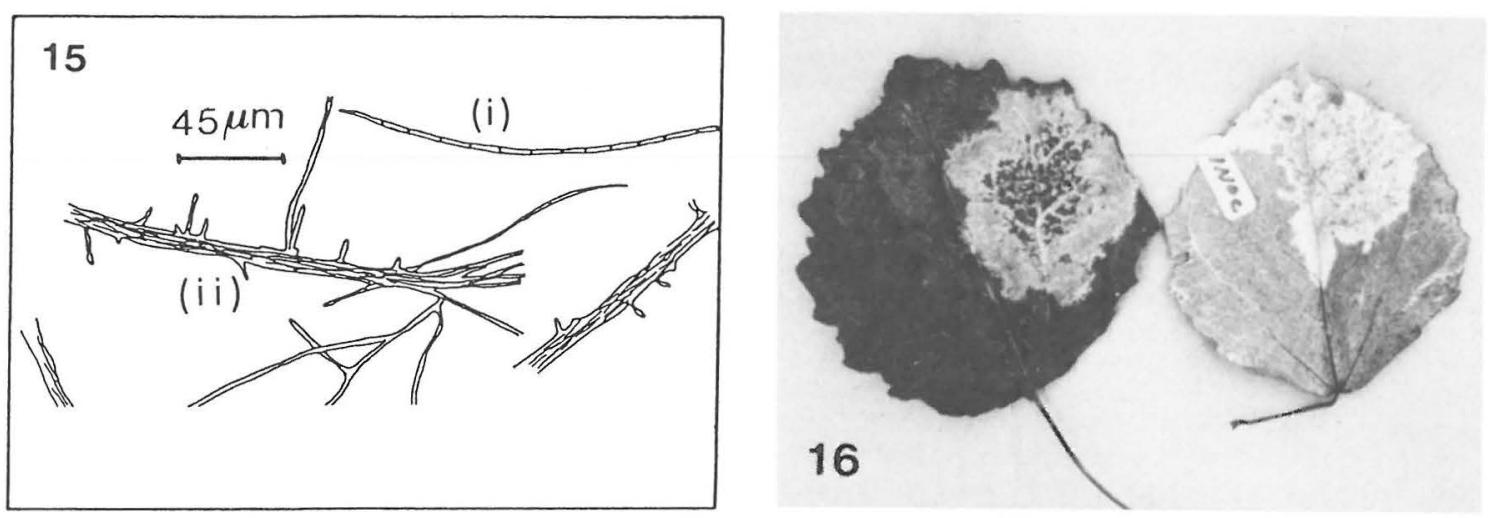

Figs. 15-16. L. ceuthocarpa. - 15: Germination of ascospores. Single spores (i) may remain ungerminated, while spore bundles (ii) are abundantly forming germ tubes. - 16: Inoculated aspen leaves. Left, the light zone around the lesion remained green after the detachment of the leaf, while the other parts turned dark when the leaf dried.

moist fallen leaves. Two or three infection spots were common, and part of or the whole leaf could be covered with lesions. Sometimes in the field, lesions on prematurely detached leaves retained their greenish grey appearance, instead of the more common dull-grey, even after overwintering. When green leaves with lesions were detached artificially, a rapid oxidation turned the green uncolonized areas black, while in the lesions a broad, one centimeterwide margin often retained its green colour (Fig. 16).

Inoculation both in the laboratory and in the field produced similar lesions within one month. When leaves were inoculated with mycelia along the main veins, the lesions enlarged rapidly in two weeks; and perithecial development readily took place during the third week in a damp chamber. Middle-aged leaves were most susceptible to all the inoculation techniques used, while in older leaves the fungus was inhibited but remained alive. Perithecial development and lesion enlargement were delayed, especially on those leaves which were inoculated when fully mature. This was also shown by placing the leaves in a lighted dew chamber where the lesions rapidly enlarged, followed by the formation of perithecia. This phenomenon was common to all the inoculations.

Re-isolation of the fungus from inoculated leaves was successful, and the development of symptoms similar to those in natural infections in the field confirmed its pathogenicity.

\section{Discussion}

The fungus $L$. ceuthocarpa in Europe occurs predominantly on the leaves of Populus tremula and has been recorded in France, Denmark, the Netherlands, Finland, Norway, Sweden, Germany, etc. In inoculation trials, it has been able to infect a wide range of poplars and their hybrids (Pinon \& Morelet 1975). The poplars of the sections Aigeiros Duby and Tacamahaca Spach are weakly infected, but with clear, more angular spots.

That the conidial stage, $A$. frondicola was not found in nature, nor formed in the leaf lesions by the strains of $L$. ceuthocarpa used in this study, does not imply its total absence in Finland. There is in fact, evidence to the contrary. This anamorph was originally described by Fries in Sweden. A. frondicola was also recorded by Sutton (1980) as causing leaf lesions in a number of European countries, one of which was Finland. His record was actually based on the specimens collected by L.E. Kari in Valkeakoski, southern Finland, on 17 August 1936 (Liro \& Roivainen 1953: 843). A similar specimen of $A$. frondicola was sent to the authors from France by Dr. J. Pinon in 1982. It seems that the morphology of the teleomorph of $L$. ceuthocarpa does not allow the division of the fungus into different species. However, differences in the form of conidia and in the affinity to produce conidia indicate that $L$. ceuthocarpa is not a uniform species but rather a collective one.

The development of the perithecia of $L$. ceuthocarpa in Finland agrees nicely with the description of Pinon and Morelet (1975) in France. $L$. tetraspora on Populus balsamifera L. in Canada also shows similar development (Thompson 1939).

Ascospore liberation during the six weeks after mid-June is well adapted to the availability in Finland of semimature, susceptible leaves in new shoots. Ejecting asci from perithecia instead of separate ascospores has also been observed in other Linospora studies (Miller \& Wolf 1936, Burnett 1976: 208). The remaining of spores in the asci or in bundles may be of special importance in the development of the fungus. Single spores rarely germinated, while the spores remaining in bundles germinated well, producing several germ tubes. Thompson (1939) also observed that single ascospores did not develop mycelial colonies. Spore bundles will certainly increase the inoculum potential of the fungus provided that they are somehow transported to susceptible leaves. Mating of compatible genomes may also occur in the bundles, which could be associated with the pathogenicity of the fungus.

In mature leaves, inoculations with spores and mycelium produced small, non-enlarging lesions up 
to one month after inoculation; however, the fungus was repeatedly isolated from the immediate margins of such lesions. This indicated a condition of 'latent' infection. A further proof of latency involved the detatchment of such leaves; placement in a dew chamber and a rapid mycelial invasion of healthy tissue, the enlargement of lesions, and the production of perithecial initials within one week were observed. The same type of development was also observed in senescent leaves in the late autumn.

Although the biochemistry of pathogenicity was not studied, it appeared that the fungus was somehow able to inhibit the functioning of normal oxidative enzymes in the leaf tissue. For mycelium, this provided free entry without defence reactions by the host. This enzymatic inhibition was observed around lesions in detatched leaves; around lesions, a broad zone remained green while oxidation in healthy tissue turned it dark. In some lesions retention of green pigment in the central part of the lesion until the following spring also occurred.

\section{References}

Burnett, J.H. 1976: Fundamentals of mycology. 2nd ed. 673 pp. London.
Eriksson, O. 1983: Outline of the ascomycetes - 1983. Syst. Ascomycetum 2: 1-37.

Jensen, W.A. 1962: Botanical histochemistry. - 408 pp. San Francisco.

Karsten, P.A. 1873: Mycologia Fennica 2. Pyrenomycetes. -Bidr. Känned. Finlands Nat.Folk 23: $1-250$

Lind, J. 1913: Danish fungi as represented in the herbarium of E. Rostrup. - 648 pp. Copenhagen.

Liro, J.I. \& Roivainen, H. 1953: Mycotheca Fennica. Fasc. 17 , no. $800-850$. - Helsinki.

Miller, J.H. \& Wolf, F.A. 1936: A leaf spot of honey locust caused by a new species of Linospora. - Mycologia 28: $171-180$.

Munk, A. 1957: Danish Pyrenomycetes. - Dansk Bot. Arkiv 17(1): 1-191.

Pinon, J. \& Morelet, M. 1975: Le Linospora ceuthocarpa (Fr.) Munk ex Morelet, parasite foliaire des peupliers. -Eur. J. For. Path. 5: 367-376.

Quraishi, M.A. \& Jamal, S.M. 1969: Fungi on Populus ciliata Wall. in Pakistan. - Pakistan J. For. 4: 429440.

Sutton, B.C. 1980: The Coelomycetes, Fungi imperfecti with pycnidia acervuli and stromata. $-696 \mathrm{pp}$. Kew.

Thompson, G.E. 1939: A leaf blight of Populus tacamahaca Mill. caused by an undescribed species of Linospora. -Canad. J. Res. 17: 232-238.

Winter, G. 1887: Die Pilze Deutschlands, Österreichs und der Schweiz 2. Ascomyceten: Gymnoasceen und Pyrenomyceten. - Rabenhorst's Kryptogamen-Flora (2nd ed.) 1: 1-928.

\section{Accepted for publication on 10 February, 1984}

